\title{
Assessment of contamination with hazardous substances in surface sediments in the Lower Danube River
}

\author{
V M Radu ${ }^{1,2}$, P Ionescu ${ }^{1,2 *}$ A A Ivanov ${ }^{1}$, Gy Deak ${ }^{1}$, E Marcu ${ }^{1}$, I E Ciobotaru ${ }^{1}$ E \\ Diacu $^{2}$ and M Pipirigeanu ${ }^{1}$ \\ ${ }^{1}$ National Institute for Research \& Development in Environmental Protection, Spl. \\ Independentei No. 294, $6^{\text {th }}$ District, Bucharest, Romania \\ ${ }^{2}$ University "Politehnica" of Bucharest, Faculty of Applied Chemistry and Materials \\ Science, 1-7 Polizu Street, 011061, Bucharest, Romania \\ *Corresponding author: petraionescu2012@yahoo.ro
}

\begin{abstract}
River ecosystems are exposed to various stressors, surface sediments as a constitutive part thereof are an essential feature for the evaluation of aquatic ecosystems status. This paper aims to assess the surface sediment quality in the lower section of the Danube River, in terms of hazardous substances content (As, Cd, Cr, $\mathrm{Cu}, \mathrm{Pb}, \mathrm{Hg}, \mathrm{Zn}, \mathrm{Ni}, \mathrm{PAH}$ and $\mathrm{PCB}$ ). For this purpose, 10 monitoring sites have been assigned for a period of September 2011-August 2017, where construction works were carried out with the purpose of improving the navigation conditions, which also involved sediment dredging. A total approximately of 1200 surface sediment samples

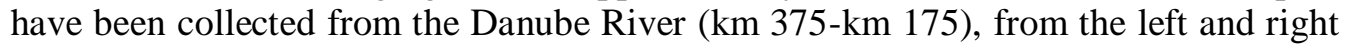
banks, monthly during the construction period (2011-2015) and quarterly in the postconstruction period (2015-2017). This study gives a description and more detailed evaluation of the integrated assessment of hazardous substances which was carried out in the surface sediments from the Lower Danube River using statistical analysis. The surface sediment quality evaluation was based on comparison of the obtained values with the chemical quality standards set out in the Romanian legislation (M.O. 161/2006). For a more in-depth assessment of the relationship between hazardous substances and for the identification of potential anthropogenic and natural sources, Principal Component Analysis (PCA) and Cluster Analysis (CA) have been used.
\end{abstract}

\section{Introduction}

The question of hazardous substances in Europe's fresh and marine waters is a complex issue, and climate change will add a further layer of complexity $[1,2]$. In the absence of relative strong measures, this phenomenon is likely to adversely affect the chemical water quality over the coming decades. Hazardous substances, like inorganic pollutants (heavy metals) and persistent organic pollutants, enter the Danube River via wastewater treatment plants, waste deposits, leaching off house hold materials and from many other sources $[3,4,5]$. Once in the Danube River, they can cause various types of damage to the ecosystem $[6,7]$. Many contaminants degrade slowly and their impacts can magnify as they accumulate in the aquatic food chain $[8,9]$.

In the last decades, some information with respect to the chemical status of Europe's surface water bodies indicate that a variety of hazardous substances pose a threat to good chemical status in Europe. 
These include certain substances, for example mercury ( $\mathrm{Hg}$ ), tributyltin (TBT) and polyaromatic hydrocarbons $(\mathrm{PAH})$, which can be described as persistent, bioaccumulative and toxic and which occur widely in the environment [10].

The implementation of a more established legislation related to chemicals has produced positive outcomes [11]. The measures have contributed to a decline in metal emissions toward water and air, whilst legislation relating to the production, use and disposal of polychlorinated biphenyls (PCB) has resulted in declines in concentrations found in marine biota. Europe has also introduced a range of relatively new laws to address the use of chemicals and their emissions to the environment, including water [12].

Surface sediments reflect all the processes occurring in the hydrographic basin, acting at the same time as a potential source of water pollutants $[13,14]$.

The studied area, the Danube sector between Calarasi and Braila $(\mathrm{km} \mathrm{375-km} \mathrm{175)} \mathrm{represents} \mathrm{an}$ important commercial navigation route which ensures the connection between the Danube River and the Black Sea.

Due to the fact that, during dry seasons, the minimum navigation depths are not respected in accordance with the Danube Commission's recommendations, in the studied area were implemented hydotechnical works that included activities such as dredging, embankments and sills that may have a potential impact on water quality and biodiversity. In order to improve the navigation conditions, during the period 2011-2017, hydrotechnical constructions on the above mentioned sector of the Danube River were performed [15]. The aim of these hydrotechnical constructions was to increase the water flow on the Old Danube thus facilitating commercial navigation during drought periods and to shorten their route to the Black Sea, by more than $100 \mathrm{~km}$. For environmental protection purposes, during the entire construction period, as well as before and after it, were analysed the evolution of the environmental factors through an intensive monitoring program. The present study has been designed to continue and to integrate past research on the region of the Lower Danube [16, 17, 18].

This paper aims to assess the surface sediment quality in the lower section of the Danube River, in terms of hazardous substances content (polyaromatic hydrocarbons - PAH, polychlorinated biphenyls $\mathrm{PCB}$, arsenium - As, cadmium - $\mathrm{Cd}$, chromium - $\mathrm{Cr}$, cooper - $\mathrm{Cu}$, lead - $\mathrm{Pb}$, mercury - $\mathrm{Hg}$, zinc - $\mathrm{Zn}$ and nickel - Ni). Some hazardous substances are hydrophobic and tend to accumulate in sediment and biota, with the result that their concentrations in these matrices are likely to be higher and, therefore, more detectable and measurable than in water. This study was made by using a set of multivariate statistical methods for surface sediment quality assessment, such as the Principal Component Analysis (PCA) and Cluster analysis (CA).

The importance of the study stems both from the sensitivity of aquatic ecosystems and from the fact that the quality of surface waters is essential for achieving sustainable development and it is vital for the long-term health, well-being and prosperity of the Danube basin population.

\section{Materials and Methods}

\subsection{Sample Source}

The study area is represented by the Lower Danube River between Calarasi and Braila $(\mathrm{km} 375$ - km 175). For this purpose, between September 2011- August 2017, approximately 1200 surface sediment samples were collected from 10 monitoring sites (Table 1).

The surface sediment samples were collected from the left and right banks, monthly during the construction period (2011 - 2015) and quarterly in the post-construction period (2015 - 2017). The samples were collected according to sampling procedures conforming to current standards and stored in PTFE recipients, in the dark and at $4{ }^{\circ} \mathrm{C}$ until being transported to the laboratory [19]. 
Table 1. Sampling monitoring sites

\begin{tabular}{|c|c|c|c|}
\hline \multirow[t]{2}{*}{ Location } & \multirow{2}{*}{$\begin{array}{l}\text { River Length } \\
(\mathrm{km})\end{array}$} & \multicolumn{2}{|c|}{ Geographical coordinates } \\
\hline & & longitude & latitude \\
\hline L1 & 347 & $27^{\circ} 34^{\prime} 9.549^{\prime \prime}$ & $44^{\circ} 11^{\prime} 24.35^{\prime \prime}$ \\
\hline L2 & 345 & & \\
\hline L3 & 344 & & \\
\hline $\mathbf{L 4}$ & 343 & & \\
\hline L5 & 340 & $27^{\circ} 37^{\prime 2} 2.349^{\prime \prime}$ & $44^{\circ} 11^{\prime} 59.10^{\prime \prime}$ \\
\hline L6 & 341 & & \\
\hline L7 & 334 & & \\
\hline L8 & 197 & $27^{\circ} 54^{\prime 2} 27.93^{\prime \prime}$ & $45^{\circ} 4^{\prime} 0.316^{\prime \prime}$ \\
\hline L9 & 196 & & \\
\hline L10 & 195 & & \\
\hline
\end{tabular}

\subsection{Procedure}

Prior to analysis, the surface sediment samples were air dried at room temperature and grinded to ensure a representative sample. From the fraction lower than $63 \mu \mathrm{m}$, around $0.5 \mathrm{~g}$ of surface sediment has been mineralized with aqua regia, using microwave digestion.

\subsection{Equipments and Materials}

To determine total element concentrations, approximately $0.5 \mathrm{~g}$ of sieved sediment was subjected to microwave assisted pressured digestion by $3: 1$ hydrochloric acid $(37 \%)$ : nitric acid $(65 \%)$ with a maximum temperature plateau of $200^{\circ} \mathrm{C}$ for 10 minutes. The obtained clear solutions were quantitatively filtered and brought to $100 \mathrm{~mL}$ with diluted nitric acid solution in ultra-pure water.

Microwave digestion of sediment samples was performed on a Milestone ETHOS Microwave System. Element concentrations in digested samples were determined using flame (FAAS) and graphite furnace (GFAAS) atomic absorption spectrometry (Solaar M5, Thermo).

All solutions were prepared using ultra-pure water from a Micropure Ultrapure water system (TKA, Germany) and Suprapur ${ }^{\circledR}$ nitric acid (65\%) purchased from Merck, Germany. Samples were filtered using $0.45 \mu \mathrm{m}$ acid hardened cellulose membrane filters (Whatman, Merck, Germany).

Analytical quality assurance was performed by the random duplicate sample method and with a river Elbe sediment certified reference material (CRM LGC 6187, UKAS reference materials, United Kingdom) periodically during each run.

\section{Results and Discussion}

In order to obtain information regarding the central tendency of hazardous substances in the studied area, statistical methods of evaluation were applied, the values obtained being also compared against the national legislation in force through the Ministerial Order 161/2006 [20].

Multivariate statistical analysis techniques were applied to the data obtained during the monitoring program using the statistical software package JMP 10.

Table 2 presents a descriptive analysis of the elements concentration using several parameters: maximum, quartile $75 \%$, median, quartile $25 \%$, minimum, mean, standard deviation, standard error mean, upper $95 \%$ mean, lower $95 \%$ mean and reference values according to the applicable legislation. 
Table 2. Statistical analysis of hazardous substances in surface sediments

\begin{tabular}{lccccccccccc}
\hline \multicolumn{1}{c}{ Pariables } & PAH & PCB & As & $\mathbf{C d}$ & $\mathbf{C r}$ & $\mathbf{C u}$ & $\mathbf{P b}$ & $\mathbf{H g}$ & $\mathbf{Z n}$ & $\mathbf{N i}$ \\
\cline { 2 - 13 } & & & \multicolumn{7}{c}{$\mathbf{U . M .}(\mathbf{m g} / \mathbf{k g})$} \\
\hline Normal values* & 1.00 & 0.02 & 29.00 & 0.8 & 100 & 40 & 85 & 0.30 & 150 & 35 \\
\hline max & 0.30 & 0.02 & 16.96 & 1.33 & 99.87 & 126.52 & 84.75 & 0.52 & 217.43 & 99.67 \\
\hline quartile 75\% & 0.14 & 0.013 & 11.27 & 0.46 & 52.30 & 43.25 & 25.81 & 0.18 & 112.39 & 43.72 \\
\hline median & 0.12 & 0.010 & 7.26 & 0.39 & 37.18 & 32.47 & 19.22 & 0.14 & 91.59 & 36.43 \\
\hline quartile 25\% & 0.11 & 0.008 & 3.14 & 0.26 & 23.00 & 24.29 & 12.37 & 0.14 & 76.13 & 30.65 \\
\hline min & 0.07 & 0.005 & 1.06 & 0.02 & 1.85 & 2.65 & 0.42 & 0.02 & 28.29 & 10.08 \\
\hline mean & 0.13 & 0.01 & 7.55 & 0.38 & 38.94 & 35.18 & 20.20 & 0.17 & 94.91 & 37.90 \\
\hline St Dev & 0.03 & 0.004 & 4.41 & 0.16 & 19.63 & 16.06 & 11.74 & 0.05 & 26.62 & 11.95 \\
\hline St Err Mean & 0.01 & 0.001 & 0.13 & 0.01 & 0.58 & 0.47 & 0.34 & 0.01 & 0.78 & 0.35 \\
\hline Upper 95\% mean & 0.13 & 0.01 & 7.81 & 0.39 & 40.07 & 36.11 & 20.87 & 0.17 & 96.45 & 38.59 \\
\hline Lower 95\% mean & 0.12 & 0.01 & 7.30 & 0.37 & 37.81 & 34.26 & 19.52 & 0.16 & 93.38 & 37.21 \\
*Normal values according to M.O. $161 / 2006[20]$ & & & & & &
\end{tabular}

From table 2 it can be observed that the data set is homogeneous for most of the evaluated indicators, with relative small differences between the minimum and the quartile $25 \%$. There are few situations where more pronounced differences appear between the maximum value and quartiles $75 \%$, but these extremes are met sporadically, at least $75 \%$ of the values being within normal limits. Values exceeding the normal values for the measured indicators being relatively isolated.

For $\mathrm{Cd}$ and $\mathrm{Hg}$, at least $97.5 \%$ of the values were found within the normal limits.

Higher occurrences of exceeding values were recorded in the case of $\mathrm{Cu}$ (maximum $126.52 \mathrm{mg} / \mathrm{kg}$ ), $\mathrm{Zn}$ (maximum $217.43 \mathrm{mg} / \mathrm{kg}$ ) and $\mathrm{Ni}$ (maximum $99.67 \mathrm{mg} / \mathrm{kg}$ ).

It is likely that $\mathrm{Ni}$ has above normal values also due to its prevalent use in the modern consumer market.

$\mathrm{Cu}$ and $\mathrm{Zn}$ may originate from anthropogenic pressures, but they are also essential micronutrients for life, part of the load may come from carry-over from the large hydrographic catchment area.

Statistical evaluation methods were applied on the complex database from the intense monitoring campaigns, comprising of the principal component analysis (PCA) and cluster analysis (CA), methods that are known to facilitate the evaluation of large number of data, generating useful and reliable information on the state of water quality.

PCA provides information on the most significant parameters based on commonalities of spatial and temporal variations that describe the whole data set by excluding the less significant parameters with a minimum loss of original variability [21, 22].

Figure 1 represents the loading plot of the first two principal components and it can be seen that most metals are comprised in the first component. PCB and As have an independent evolution compared to metals, which could either suggest a common source of provenance or be explained based on the known affinity of As for the inclusion in complex organic substances. 


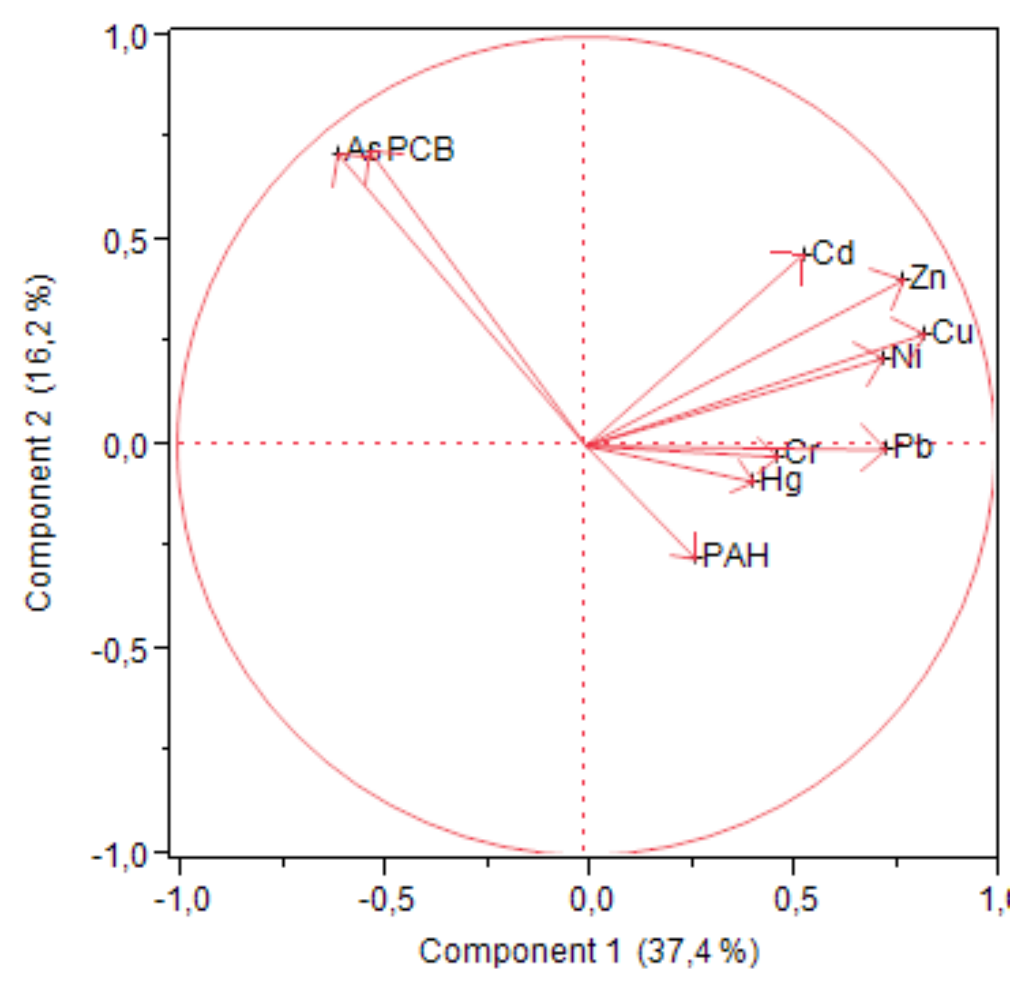

Figure 1. Loading plot for hazardous substances

Figure 2 represents the score plot of the principal components and shows the data coagulation patterns for hazardous substances.

The first principal component (PC1) represents $37.40 \%$ from the variability of the entire data set and the second principal component (PC2) supplemented by $16.20 \%$ the coverage of the original variance. This fact indicated that probably the first component contained metals from the common source of historical alluvia supplied by the river, and the second principal component probably contains more independently-variable organic substances.

After analysing the coagulated groups, we observed the following tendencies: samples from the score group blue are sampled in an autumn period, samples from the score group green are sampled in a winter period, samples from the score group yellow are sampled in a spring period and samples from the score group red are sampled in a summer period. Samples with the scores black do not belong to any of the identified groups and are anomalies that occur in a monitoring program. 


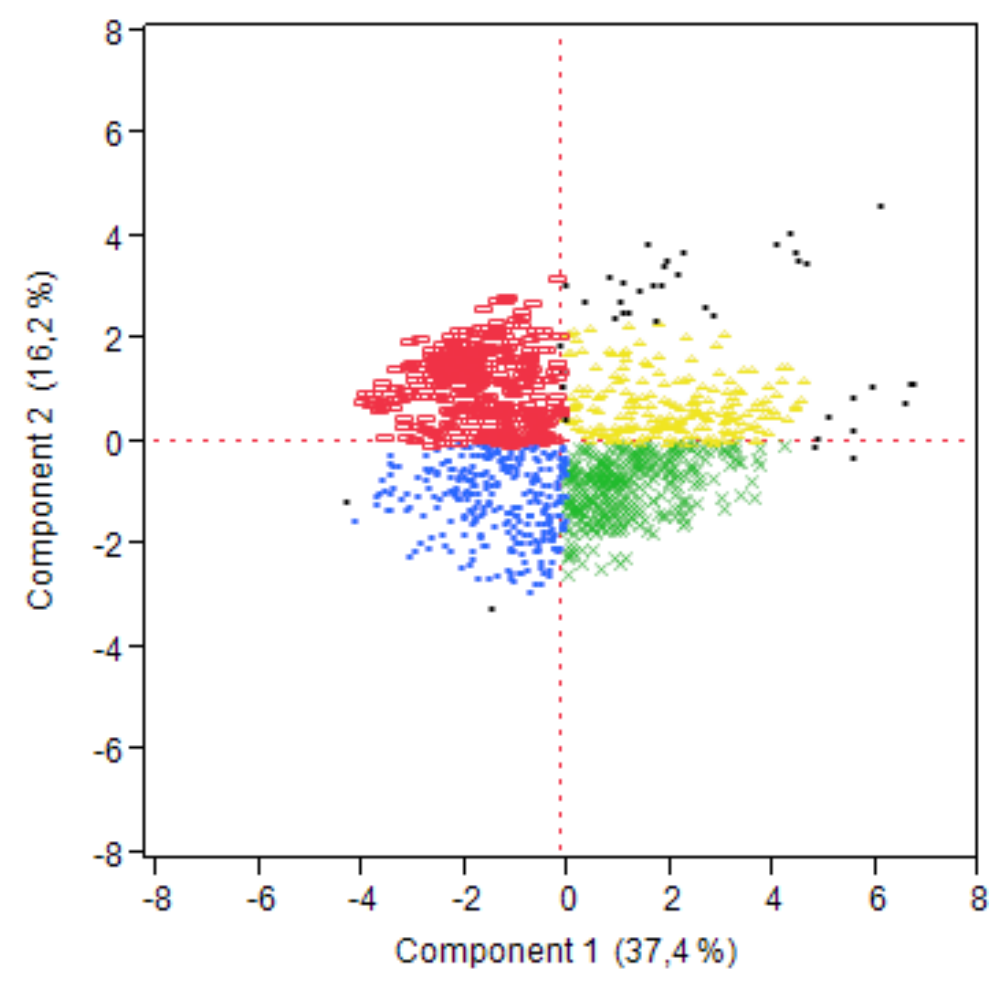

Figure 2. Score plot for hazardous substances

Cluster analysis is another type of multivariate analysis providing details of similarities between groups of parameters $[3,24,25]$.

For a more detailed assessment of the relationship between hazardous substances and for identification of anthropogenic and natural sources, Cluster Analysis (CA) has been used. The results are illustrated by a hierarchical dendrogram as shown in figure 3 .

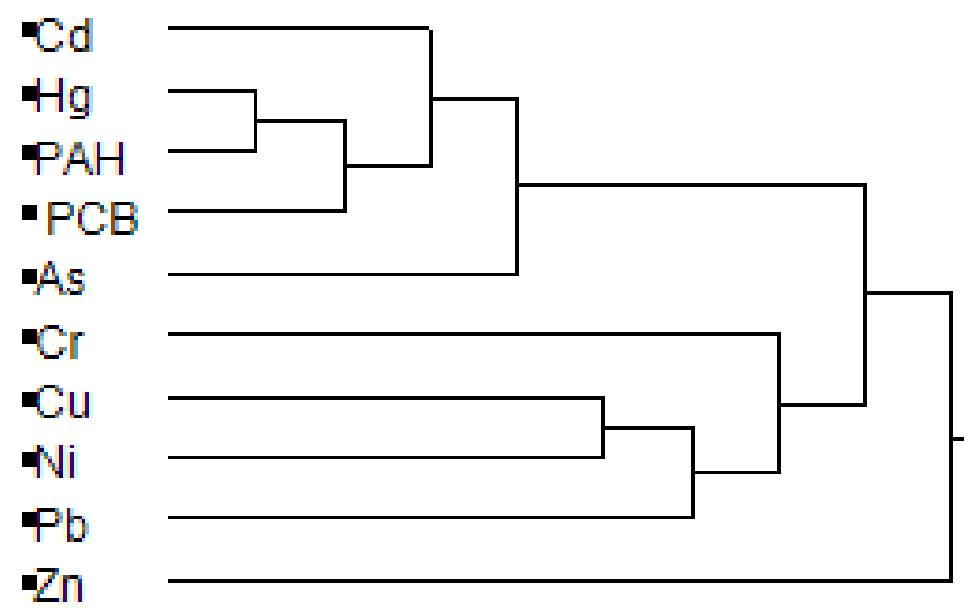

Figure 3. Dendrogram of hazardous substances 
Depending on the degree of association between hazardous substances, two distinct clusters could be identified (Fig. 3): the first group includes $\mathrm{Hg}, \mathrm{Cd}$, As, PAH and PCB supporting a common origin and the second group $\mathrm{Cu}, \mathrm{Ni}, \mathrm{Pb}, \mathrm{Zn}$ and $\mathrm{Cr}$. Overall the clusters seemed to indicate the presence of both natural and anthropogenic hazardous substances sources of origin.

\section{Conclusions}

The data set is homogeneous for most of the evaluated indicators, there are few isolated situations where the values exceeded the normal limits. Higher occurrences of values above the limits were recorded in the case of $\mathrm{Cu}$ (maximum $126.52 \mathrm{mg} / \mathrm{kg}$ ), $\mathrm{Zn}$ (maximum $217.43 \mathrm{mg} / \mathrm{kg}$ ) and $\mathrm{Ni}$ (maximum $99.67 \mathrm{mg} / \mathrm{kg}$ ).

From PCA analysis, the first component represents (PC1) $37.40 \%$ from the variability of the entire data set and the second principal component (PC2) supplemented by $16.20 \%$ the coverage of the original variance.

From $\mathrm{CA}$ analysis, one may observe that the first group includes $\mathrm{Hg} \mathrm{Cd}, \mathrm{As}, \mathrm{PAH}$ and PCB supporting a common origin and the second group $\mathrm{Cu}, \mathrm{Ni}, \mathrm{Pb}, \mathrm{Zn}$ and $\mathrm{Cr}$.

Overall, the evaluated ecosystem is not severely affected by new significant accidental discharges, the presence of hazardous substances in surface sediments presenting a mostly homogeneous evolution.

\section{Acknowledgments}

This work used data obtained through the POST contract "Monitoring of Environmental Impact of the Works for Improvement of the Navigation Conditions on the Danube between Calarasi and Braila, km 375 - km 175", available on-line (http://www.afdj.ro/en/content/romomed). The authors would like to thank the management and employees of National Institute for Research and Development in Environmental Protection for their valuable assistance and suggestions. Violeta-Monica Radu's contribution was partially financed by the Operational Programme Human Capital of the Ministry of European Funds through the Financial Agreement 51668/09.07.2019, SMIS code 124705.

\section{References}

[1] Mocanu-Vargancsik C A and Barbulescu A, 2019 IOP Conf. Series: Journal of Physics: Conf. Series 1297, 5th International Scientific Conference SEA-CONF

[2] Healthy Workplaces Manage Dangerous Substances, Campaign Guide 2018 EU-OSHA European Agency for Safety and Health at Work

[3] ICPDR, 2018 Hazardous substances pollution in the Danube River Basin, https://dunaregiostrategia.kormany.hu

[4] Pavlovića P, Markovića M, Kostića O, Sakanc S, Đorđevićc D, Perovića V, Pavlovića D, Pavlovića M, Čakmaka D, Jarića S, Paunovićb M and Mitrovića M, 2019 Catena 174 399-412

[5] Burada A, Topa C M, Georgescu L P, Teodorof L, Nastase C, Seceleanu-Odor D and Iticescu C, 2015 Rev. Chim. (Bucharest) 66 1725-1727

[6] Zessner M, 2011 7th EWA Annual Brussels Conference - "Effective Urban Waste Water Treatment - a key prerequisite for successful implementation of the Water Framework Directive", 25th October Brussels, Belgium

[7] Steckbauer A, Duarte C M, Carstensen J, Vaquer-Sunyer R and Conley D J, 2011, Environ. Res. Lett. 6

[8] Diepens N J and Koelmans A A, 2018 Environmental Science \& Technology 52 8510-8520

[9] HELCOM, 2017 The integrated assessment of hazardous substances - supplementary report to the first version of the 'State of the Baltic Sea' report. Available at: http://stateofthebalticsea.helcom.fi/about-helcom-and-the-assessment/downloads-and-data/ 
[10] Iordache M, Meghea A, Neamtu S, Popescu L R and Iordache I, 2014 Rev. Chim. (Bucharest) 65 87-93

[11] Lapworth D J, Lopez B, Laabs V, Kozel R, Wolter R, Ward R, Vargas Amelin E, Besien T, Claessens J, Delloye F, Ferretti E and Grath J, 2019, Environ. Res. Lett. 14

[12] EEA Technical report, 2011, Hazardous substances in Europe's fresh and marine waters An overview 8 1-61

[13] Ionescu P, Radu V-M and Diacu E, 2015, Rev. Chim. (Bucharest) 66 1725-1727

[14] Pacle Decena S C, Arguelles M S and Liporada Robel L, 2018, Pol. J. Environ. Stud. 27 19839-1995

[15] POS-T Project Monitoring of Environmental Impact of the Works for Improvement of the Navigation Conditions on the Danube between Calarasi and Braila, km 375 - km 175, http://www.afdj.ro/en/content/romomed

[16] Deak Gy, Badilita A M, Danalache T and Tudor M, 2014, Journal of Environmental Protection and Ecology 15 954-964

[17] Ionescu P, Radu V-M, Deak Gy and Diacu E, 2014, Rev. Chim. (Bucharest) 65 1092-1095

[18] Radu V-M, Ivanov A A, Deak Gy and Diacu E, 2016, Rev. Chim. (Bucharest) 67 649-653

[19] ***EN ISO 5667-12 2017 Water quality. Sampling. Part 12: Guidance on sampling of bottom sediments from rivers, lakes and estuarine areas

[20] ***Ministerial Order No. 161, 2006, Approving the Norms on surface water quality classification to determine the ecological status of water bodies

[21] Diamantini E., Lutz S R, Mallucci S, Majone B, Merz R and Bellin A, 2018, Science of the Total Environment 612 49-62

[22] Uncumusaoğlu A A and Mutlu E, 2019, Pol. J. Environ. Stud. 28 1-14

[23] Dołęgowska S and Michalik A, 2019, Environmental Monitoring and Assessment 191302

[24] Hora Alves J P, Fonseca L C, Alves Chielle R S and Barreto Macedo L C, 2018 RBRH, Porto Alegre 23 1-12

[25] Salah E A M, Turki A M and Al-Othman E M, 2012, Journal of Environmental Protection 3 $1629-1633$ 